\title{
Immunoneutralization of Endogenous Aminoprocalcitonin Attenuates Sepsis-Induced Acute Lung Injury and Mortality in Rats
}

\author{
Eva Tavares, ${ }^{*}$ Rosario Maldonado, ${ }^{*}$ and Francisco J. Miñano*
}

From the Clinical and Experimental Pharmacology Research Unit, * Valme University Hospital, and the Department of Pharmacology, Pediatrics and Radiology ${ }^{\dagger}$ Faculty of Medicine, University of Seville, Seville, Spain

\author{
Accepted for publication \\ July 7, 2014. \\ Address correspondence to \\ Francisco J. Miñano, M.D., \\ Ph.D., Department of Pharma- \\ cology, Pediatrics and Radi- \\ ology, Faculty of Medicine, \\ University of Seville, Avda \\ Sánchez Pizjuán, s/n, Seville \\ 41009, Spain. E-mail: \\ jminano@us.es.
}

\begin{abstract}
Acute lung injury (ALI) secondary to sepsis is a complex syndrome associated with high morbidity and mortality. We report that aminoprocalcitonin (NPCT), an endogenous peptide derived from the prohormone procalcitonin, plays a critical role in the development of ALI during severe sepsis and is a suggested risk factor for sepsis morbidity and mortality. Lethal sepsis was induced in rats by cecal ligation and puncture (CLP). Two hours after CLP, an i.p. injection of $200 \mu \mathrm{g} / \mathrm{kg}$ of anti-rat NPCT antibody was followed by continuous infusion of anti-NPCT (16 $\mu \mathrm{g}$ per hour) via a minipump for 18 hours. Samples were harvested 20 hours after CLP. High expressions of the CALCA gene, procalcitonin, and NPCT were detected in the lung tissue of rats with severe sepsis. Immunoneutralization of NPCT decreased pulmonary levels of CALCA, procalcitonin, and NPCT; reduced lung inflammation and injury, neutrophil infiltration, and bacterial invasion; and improved survival in sepsis. Anti-NPCT treatment also suppressed sepsis-induced inflammatory cytokine expression, cytoplasmic degradation of the inhibitor of NF- $\kappa B, I \kappa B \alpha$, and nuclear NF- $\kappa B$ translocation in lung tissues. Therapeutic benefits of anti-NPCT were also associated with increased pulmonary levels of the anti-inflammatory cytokine IL-10. These data support a pathogenic role for NPCT in sepsis and suggest NPCT as a potential new target for clinical prevention and treatment of ALI in severe sepsis. (Am J Pathol 2014, 184: 3069-3083; http:// dx.doi.org/10.1016/j.ajpath.2014.07.025)
\end{abstract}

Sepsis and septic shock are among the most common causes of death in critically ill patients. ${ }^{1}$ Under those conditions, the ultimate cause of death is usually not due to progression of the infection itself, but rather is secondary to development of multiple organ dysfunctions. ${ }^{2}$ The respiratory system is the most frequently affected organ system, and diffuse inflammation of lung parenchyma and severe lung dysfunction are the first steps in the development of multiple organ failure and one of the leading causes of death in sepsis. Nearly $50 \%$ of patients with severe sepsis will develop acute lung injury (ALI) and its more severe form, acute respiratory distress syndrome (ARDS). ${ }^{3,4}$ Despite significant advances in our understanding of the pathophysiological features of sepsis, ALI caused primarily by nonpulmonary sepsis remains a major clinical problem, with serious morbidity and mortality. ${ }^{5}$

ALI is characterized by a disturbance of the alveolarcapillary barrier, resulting in increased lung permeability and recruitment of polymorphonuclear neutrophils (PMNs) into the lung. ${ }^{5}$ Although mechanisms underlying the development of ALI are not clearly understood, it is the infiltration of PMNs and activation of inducible transcription factors in the lungs, such as NF- $\kappa \mathrm{B}$, that is thought to lead to the pulmonary dysfunction and the development of ALI. ${ }^{6-8}$ Activation of $\mathrm{NF}-\kappa \mathrm{B}$ leads to the activation of various proinflammatory and chemotactic molecules, such as tumor necrosis factor (TNF)- $\alpha$, IL-1 $\beta$, and macrophage inflammatory protein 2 (MIP-2), critical in the progress of lung inflammation/ injury. ${ }^{9,10}$ On the other hand, the release of anti-inflammatory cytokines, in particular IL-10, is related to the protection of

\footnotetext{
Supported by Andalusia Government grant 293/2010 and Spanish Ministry of Health grants FIS 09/1563 and FIS 12/01074 (E.T.).

E.T. and R.M. contributed equally to this work.

Disclosures: None declared.
} 
cells, the down-regulation of proinflammatory cytokines, and the prevention of lung injury. ${ }^{11,12}$

Severity and mortality of sepsis have also been associated with high concentrations of procalcitonin (ProCT) and its bioactive peptide, aminoprocalcitonin (NPCT). ${ }^{13}$ ProCT is a 116-amino acid peptide that has an approximate molecular weight of $14.5 \mathrm{kDa}$ and belongs to the calcitonin (CT) superfamily of peptides, including calcitonin gene-related peptides, adrenomedullin, and amylin. ${ }^{14}$ These peptides function as ligands for a complex family of $\mathrm{G}$ protein-coupled receptors consisting of the calcitonin receptor (CALCR), calcitonin receptor-like receptor (CALCRL), and three receptor-associated modified proteins. ${ }^{15}$

ProCT is encoded by the human CALCA gene located on chromosome $11 .{ }^{16}$ The original product of the $C A L C A$ gene is a 141-amino acid chain of preprocalcitonin, which is responsible for the production of ProCT. This propeptide is further processed to NPCT, immature CT, and CT carboxylterminus peptide-I (or katacalcin). ${ }^{17}$ CALCA gene products and their receptors are found throughout the body and are abundantly expressed in nonneuroendocrine cells of the lungs during sepsis. ${ }^{18-20}$ NPCT, unlike its precursor and CT carboxyl-terminus peptide-I, is a highly evolutionarily conserved peptide in all mammal species studied, ${ }^{21}$ which suggests an important role on a biological level.

NPCT is a single-chain 57-amino acid peptide with a molecular weight of approximately $8 \mathrm{kDa}$. It was first identified in human and medullary thyroid carcinoma cells. ${ }^{22,23}$ Subsequent studies identified NPCT as the most abundant CALCA gene product in the plasma of normal subjects and of medullary thyroid carcinoma and septic patients. ${ }^{24,25}$ Recent prospective studies indicate that baseline ProCT and NPCT levels were associated with all-cause and cancer mortality in apparently healthy men with no previous history of cancer. ${ }^{26}$ However, essentially nothing is currently known regarding the physiological and pathophysiological role of ProCT or its associated peptides as biomediators in carcinogenesis.

Under normal metabolic conditions, all of the ProCT is formed in the thyroid $\mathrm{C}$ cells and in the pulmonary neuroendocrine cells of the lungs and is converted into CT, so that small amounts of ProCT or its associated peptides are found in the peripheral circulation of healthy subjects. ${ }^{27}$ In the systemic inflammatory response syndrome (SIRS) associated with severe infections and sepsis, nonneuroendocrine tissues also express the CALCA mRNA and high amounts of ProCT and NPCT are produced from all parenchymal tissues and differentiated cells types throughout the body. ${ }^{28}$ Thus, significant concentrations of these peptides can be detected in the blood of patients with severe bacterial infection/sepsis. More important, their levels persist for relatively long periods of time and correlate with sepsis severity and mortality. ${ }^{29}$

Parenchymal cells (including liver, lung, kidney, adipocytes, and muscle) provide the largest tissue mass and principal source of circulating ProCT in sepsis. The inflammatory release of ProCT can be induced either directly, via microbial toxins (eg, endotoxin), or indirectly, via a humoral or cellmediated host response (eg, IL-1 $\beta$, TNF- $\alpha$, and IL- 6 ). ${ }^{30,31}$ However, the function of ProCT synthesized in the nonneuroendocrine tissues under microbial infection is presently unclear. The details of these mechanisms are unknown, and several unanswered questions that merit further studies remain, including the pathophysiological role of NPCT that circulates at high concentrations in sepsis.

NPCT was initially described as a neuroendocrine peptide with bone cell mitogen activity. ${ }^{23}$ Subsequent studies suggest that NPCT is also involved in the SIRS. Under normal metabolic conditions, NPCT is constitutively expressed in brain regions involved in the control of energy homeostasis. ${ }^{32,33}$ It was also observed that central administration of NPCT simulates the inflammatory responses that occur in sepsis (fever, anorexia, and weight reduction) via activation of hypothalamic prostaglandin-dependent pathways, ${ }^{34}$ and corticotrophin and melanocortin neurons, where CALCR/ CALCRL are abundantly expressed. ${ }^{20,35}$ Recent studies suggest that NPCT is actively involved as a mediator of disease progression and severity in sepsis.

Prophylactic or therapeutic neutralization of endogenous NPCT with monoclonal or specific polyclonal antibodies raised against a highly conserved amino acid sequence of NPCT decreases the early production of proinflammatory cytokines (IL-1 $\beta$ and TNF- $\alpha$ ), increases the late production of protective anti-inflammatory factors (IL-10 and adrenocorticotropic hormone), and reduces the mortality of rats after a lethal dose of endotoxin. ${ }^{13}$ These studies indicate that NPCT aggravates inflammatory responses and mediates immune suppression after the induction of sepsis, likely contributing to the increased mortality seen in a rat model of lethal endotoxemia. However, it remains unknown whether therapeutic neutralization of NPCT has any protective effects on severe sepsis-induced ALI and, if so, the potential mechanism(s) responsible for its benefit. We tested the hypothesis that endogenous NPCT plays a role in the pathogenesis of indirect ALI caused primarily by nonpulmonary sepsis, the first step in the development of multiple organ failure and one of the leading causes of death in sepsis. We also postulated that neutralization of endogenous NPCT attenuates severe sepsis-induced ALI. Therefore, we established a rat model of lethal sepsis induced by cecal ligation and puncture (CLP), in which bacterial dissemination and growth leads to organ damage, to assess the role of NPCT and the related molecular mechanisms associated with NPCT in modulating lung inflammatory responses.

\section{Materials and Methods}

\section{Animal Model of Sepsis}

Male Wistar rats (280 to $300 \mathrm{~g}$; Harlan Iberica, Barcelona, Spain) were individually housed in a temperature-controlled 
room on a 12-hour light/dark cycle and fed a standard rat chow diet (2014S Teklad; Harlan Iberica). Rats were acclimatized for at least 7 days before experiments. Male animals were starved for 14 hours before any intervention. Severe sepsis was induced by CLP, an animal model that has high clinical relevance to humans, because it reproduces many hallmarks of sepsis that occur in patients. ${ }^{36,37}$ To perform this procedure, rats were anesthetized with an i.p. mixture of $100 \mathrm{mg} / \mathrm{kg}$ ketamine and $5 \mathrm{mg} / \mathrm{kg}$ xylazine (Sigma-Aldrich, St. Louis, MO). After shaving the abdominal fur and preparing the abdominal wall with $10 \%$ povidone-iodine solution, cecum was exposed via a $2-\mathrm{cm}$ ventral midline abdominal incision and ligated below the ileocecal valve to avoid intestinal obstruction. The ligated part of the cecum was then punctured twice with a 16-gauge needle, and a small amount of cecal contents was expressed through the punctures. After repositioning of the bowel, the incision was closed, and $3 \mathrm{~mL} / 100 \mathrm{~g}$ body weight of prewarmed sterile saline was administered s.c. No antibiotics were administered. Sham-operated on animals (ie, control animals) underwent the same procedure with the exception that the cecum was neither ligated nor punctured. To ensure consistency, the same surgeon (R.M.) performed all of the above manipulations. Postoperatively, all rats had unlimited access to food and water. Animals were sacrificed 20 hours after CLP or sham operation for collection of tissue samples. All experiments were performed in accordance with the Council of the European Communities' Directive (86/609/ European Economic Community) and Spanish regulations (Boletin Oficial del Estado/67:8509/1988) for the use of experimental animals. The Animal Care and Use Committee of the University of Seville (Seville, Spain) approved the protocol.

\section{Immunoneutralization of Endogenous NPCT}

To examine an involvement of NPCT in sepsis-induced lung inflammation, a rabbit anti-rat antibody raised against a highly conserved terminal region of human and rat NPCT (amino acids 44 to 57) was used. The ability of this antibody to block the in vivo activity of endogenous NPCT in rats and its specificity on rat brain sections by preabsorption with the peptide have been previously reported. ${ }^{20,35}$ Control rabbit nonimmune IgG was used as control (Sigma-Aldrich). AntiNPCT and control IgG were dissolved in phosphatebuffered saline (PBS; $\mathrm{pH}$ 7.4) to a final concentration of $2.0 \mathrm{mg} / \mathrm{mL}$. All solutions were passed through $0.22-\mu \mathrm{m}$ pore-size Millipore filters and stored at $-80^{\circ} \mathrm{C}$. The same batches and solutions were used for all experiments and contained an endotoxin level $<0.1 \mathrm{ng} / \mathrm{mL}$ of protein (ie, lower than the detection limit of endotoxin assay) measured by the Limulus amebocyte lysate method, as previously described. ${ }^{13}$

A $200-\mu \mathrm{L}$ Alzet osmotic minipump ( $8 \mu \mathrm{L}$ per hour delivery rate; model 2001D; Durect, Cupertino, CA) was placed intradermally in the peritoneal skin and a polyethylene catheter of the pump was inserted into the peritoneum at the time of surgery. Before implantation, pumps were prefilled $(2.0 \mu \mathrm{g}$ protein $/ \mu \mathrm{L})$ with anti-NPCT antibody or control IgG solution and primed in sterile PBS for 2 hours at $37^{\circ} \mathrm{C}$. After an i.p. injection of $200 \mu \mathrm{g} / \mathrm{kg}$ of the appropriate antibody 2 hours after CLP, the minipump was then connected to the catheter inserted into the peritoneum. The total dose of anti-NPCT or control IgG each rat received was approximately $1200 \mu \mathrm{g} / \mathrm{kg}$ body weight. The concentration of anti-NPCT was determined by performing a dose-response curve for the antibody in a separate set of animals and by selecting the concentration that significantly improved survival 24 hours after CLP (Supplemental Figure S1).

\section{Experimental Procedures}

We randomly divided animals into three groups $(n=10$ per group): i) control sham-operated on animals, ii) control IgG antibody plus CLP, and iii) anti-NPCT plus CLP. Because severe sepsis and multiple organ dysfunctions occurred at 20 hours after CLP, ${ }^{38}$ we chose this time point to assess lung injury. Twenty hours after CLP (ie, 18 hours after implantation of the minipump), the rats were anesthetized. Cardiac puncture was used for collecting blood samples, and peritoneal fluid was collected as described below. Then, the lungs were surgically exposed and allowed to collapse freely, after which the trachea was carefully intubated. The tracheal cannula was connected to a syringe and a water-graded column, and the lungs were inflated with air at a pressure of 15 to 20 $\mathrm{cm} \mathrm{H}_{2} \mathrm{O}$. Care was taken to prevent overinflation and alveolar damage. The main bronchus was tied and the cardiopulmonary tract, including the lower part of the trachea, was carefully extracted from the rib cage and placed in a sterile ice-cold Ringer's lactate solution. The heart was withdrawn, and the entire lung was carefully removed to avoid pleural rupture and blood contamination of the airways. The upper and lower lobes of the left lung were then divided. The lower lobes of the left lung were snap frozen in liquid nitrogen and stored at $-80^{\circ} \mathrm{C}$ for gene expression analysis, protein extraction, cytokine determination, and myeloperoxidase (MPO) activity measurement. The left upper lobes were used to obtain the wet/dry (W/D) ratio. Right lungs were used for histological analysis. The survival rate was also investigated in separate experiments.

\section{Measurement of Pulmonary Edema}

The lung water content was assessed by the W/D weight ratio. Freshly harvested upper lobe of left lung was washed three times with $\mathrm{PBS}$ at $4^{\circ} \mathrm{C}$ to remove residual blood, gently dried using blotting paper, and weighed to obtain the wet lung weight $(\mathrm{W})$. The wet lungs were then dried in a drying oven at $70^{\circ} \mathrm{C}$ for 48 hours, after which they were 
weighed again to obtain the dry lung weight (D). The W/D ratio was calculated as follows:

$\mathrm{W} / \mathrm{D}$ ratio $(\%)=[($ wet weight - dry weight $) /$ dry weight $] \times 100$.

\section{Histological Assessment of Lung Injury}

For histological evaluation, the right lung was dissected and fixed immediately in $10 \%$ neutral-buffered formalin, embedded in sucrose, frozen in dry ice using optimum cutting temperature medium, cryosectioned (5 $\mu \mathrm{m}$ thick), and stained with hematoxylin and eosin. All of the procedures were performed according to previously published methods. ${ }^{39}$ A pathologist who was blinded to the experimental conditions examined all of the sections. The histopathological evaluation was performed under a light microscope using a grid system. A scoring system to grade the degree of lung injury was used, on the basis of the following histological features: edema, hyperemia and congestion, neutrophil margination and tissue infiltration, intraalveolar hemorrhage and debris, and cellular hyperplasia. Each feature was graded from 0 to 3 on the basis of its absence ( 0 ) or presence to a mild (1), moderate (2), or severe (3) degree. ${ }^{40}$ Overall lung injury was categorized according to the sum of the score ( 0 to 3 : normal to minimal injury; 4 to 6 : mild injury; 7 to 9: moderate injury; 10 to 12 : severe injury). The maximum possible score per animal was 12. PMN accumulation in lungs was quantitated by counting PMNs at the alveolar septal walls in five randomly selected nonoverlapping fields from each stained section of the individual lungs. PMNs were identified as cells with multilobed nuclei exhibiting lighter-red nuclear staining than surrounding the cells. PMN entrapment was expressed as the mean number of PMNs per 10 high-powered fields at $\times 1000$ magnification.

\section{Analysis of MPO Activity in Lung Tissues}

MPO activity, an indicator of PMN accumulation in lungs, was determined as previously described. ${ }^{39}$ Lung tissues were weighed and homogenized $(50 \mathrm{mg} / \mathrm{mL})$ in $50 \mathrm{mmol} / \mathrm{L}$ potassium phosphate $(\mathrm{pH}$ 6) containing $5 \mathrm{mmol} / \mathrm{L}$ hexadecyltrimethylammonium bromide (Sigma-Aldrich) and subjected to three cycles of freezing and thawing, followed by centrifugation at $30,000 \times g$ for 20 minutes at $4^{\circ} \mathrm{C}$ to obtain the supernatant. MPO activity was determined by combining 20 $\mu \mathrm{L}$ tissue supernatant with $60 \mu \mathrm{L}$ assay buffer containing $0.167 \mathrm{mg} / \mathrm{mL}$ O-dianisidine dihydrochloride (Sigma-Aldrich) and $0.0005 \%$ hydrogen peroxide. The MPO activity was measured using a biophotometer spectrophotometer at $450 \mathrm{~nm}$ (Thomas Scientific, Swedesboro, NJ). The MPO activity was calculated as the change in absorbance $(\Delta \mathrm{A})$ at $450 \mathrm{~nm}$ over 1 minute and expressed as $\Delta \mathrm{A}_{450} /$ minute per gram of protein.

\section{Measurement of Circulating Blood and Peritoneal PMNs}

Blood and peritoneal fluid were obtained as described above for bacterial load. Whole blood for PMN count was collected into sterile tubes containing potassium EDTA and counted on an automated hematology cell counter (Cell-Dyn 3500; Abbott Laboratories, Abbott Park, IL), as previously described. ${ }^{41}$ Peritoneal fluid was mixed with Turks solution (0.2 mg methylene blue in $1 \mathrm{~mL}$ glacial acetic acid, $6.25 \%$ $\mathrm{v} / \mathrm{v}$ ) in a 1:10 dilution. PMNs were then counted under a light microscope using a Burker chamber.

\section{Bacterial Load}

To determine the bacterial load in the peritoneum, the peritoneal cavity was lavaged with $5 \mathrm{~mL}$ of sterile saline. Serial log dilutions were made. To determine the bacterial load in the blood, $100 \mu \mathrm{L}$ of blood was collected and serially diluted with sterile saline. To determine the pulmonary bacterial load, the lungs were harvested and equal amounts of wet tissue were homogenized and briefly centrifuged to remove gross particulate matter. Serial log dilutions of tissue homogenates were applied. A portion $(500 \mu \mathrm{L})$ of each dilution was then plated on blood agar plates and incubated at $37^{\circ} \mathrm{C}$ for 24 hours under aerobic conditions. Total bacterial counts were determined after plating of serial dilutions of lavage fluid or organ extracts on blood agar, according to dilution factor and number of bacterial colonies. Results were expressed as colony-forming units (CFUs) per milliliter or gram of wet tissue.

\section{Determination of Pulmonary Cytokine Levels}

For cytokine determination, protein extracts were isolated by homogenization of lungs $(50 \mathrm{mg}$ tissue $/ \mathrm{mL})$ in $50 \mathrm{mmol} / \mathrm{L}$ Tris-HCl, pH 7.4, with $0.5 \mathrm{mmol} / \mathrm{L}$ dithiothreitol, and $10 \mu \mathrm{g} /$ $\mathrm{mL}$ of a cocktail of proteinase inhibitors (Roche Diagnostics, Basel, Switzerland), as previously described. ${ }^{42}$ Samples were centrifuged at $30,000 \times g$ for 20 minutes and stored at $-80^{\circ} \mathrm{C}$ until cytokine determination. Murine IL-1 $\beta$, IL-6, IL-10, TNF- $\alpha$, MIP-2, and regulated on activation, normal T-cell expressed and secreted (RANTES) levels in supernatants were measured using a Luminex customized rat 6-plex cytokine assay kit, according to the manufacturer's instructions (Procarta Cytokine Assay Service; Affymetrix, Santa Clara, CA). Data were analyzed and normalized to the protein concentration in the sample using Bio-Plex Manager software version 5.0 (Bio-Rad Laboratories, Hercules, CA). The detection limit was $1.2 \mathrm{pg} / \mathrm{mL}$.

\section{Protein Extraction and Quantification}

Frozen pulmonary tissues were homogenized at $4^{\circ} \mathrm{C}$ in a lysis buffer containing $50 \mathrm{mmol} / \mathrm{L}$ Tris-HCl, $5 \mathrm{mmol} / \mathrm{L}$ EDTA, $2 \%$ SDS, and a protease inhibitor cocktail (Roche Diagnostics). Tissue homogenates were centrifuged at $5000 \times g$ for 15 minutes at $4{ }^{\circ} \mathrm{C}$ to clear the cellular debris. Total protein content in the homogenate was extracted using the Tripure Isolation Reagent (Roche Diagnostics) in accordance with the manufacturer's instructions. The protein pellets were 
resuspended in $4 \%$ SDS and $8 \mathrm{~mol} / \mathrm{L}$ urea in $40 \mathrm{mmol} / \mathrm{L}$ Tris- $\mathrm{HCl}(\mathrm{pH} 7.4)$ and rotated overnight at room temperature for total dilution. Protein quantification in soluble fractions was determined by the Bio-Rad Protein Assay (Bio-Rad Laboratories, Inc.) and spectrophotometry. Real-time PCR determined lung expression of CALCA mRNA. Pulmonary levels of ProCT, NPCT, $\mathrm{NF}-\kappa \mathrm{B}$, and I $\mathrm{B} \alpha$ proteins were measured by immunoblotting, as described below.

\section{Real-Time PCR Assay for CALCA Gene Expression in the Lung}

Real-time PCR was performed as described previously. ${ }^{13,20}$ Briefly, total RNA was extracted from lung homogenates using Tripure reagent (Roche Diagnostics) and then reverse transcribed into cDNA using the Quantitect Enzyme Reverse Transcriptase Kit (Qiagen, Hilden, Germany), according to the manufacturer's instructions. SYBR Green real-time RT-PCR was performed with the Stratagene Mx3005P sequence detection system (Agilent Technologies, Madrid, Spain) using SensiMix SYBR Low-ROX (Bioline GmbH, Luckenwalde, Germany). Primers for CALCA were designed using Beacon Designer software version 5.1 (Premier Biosoft, Palo Alto, CA), according to the rat CALCA sequence NM_017338 (National Center for Biotechnology Information Database). The primers were as follows: forward, 5'-CGCTGCCCAGATCAAGAGTC-3'; reverse, 5'-AGATGCTGACAACCAGGAAAGG-3' (Eurogentec S.A., Liege, Belgium). The primers for the reference gene GAPDH (Rn_Gapd_1_SG) were predesigned and validated by Qiagen (QuantiTect Primer Assay). Threshold cycle values were determined automatically using MxPro software version 3.20 (Stratagene, La Jolla, CA). Primer specificity was verified by melt curve analysis. Relative gene expression was determined using the $2-\Delta \Delta C_{T}$ method. All values for gene expression after PCR analysis are expressed as relative to glyceraldehyde-3-phosphate dehydrogenase (GAPDH) mRNA content and referred to as relative expression.

\section{Isolation of Nuclear and Cytosolic NF- $\kappa$ B Proteins}

Subcellular fractionation of lung cells to determine the expression of nuclear and cytoplasmic NF- $\mathrm{KB}$ p65 and cytoplasmic I $\mathrm{K} \mathrm{B} \alpha$ from lung tissues was performed by sequential density centrifugation. ${ }^{43}$ The lungs were snap frozen in liquid nitrogen 20 hours after CLP or sham operation and homogenized in ice-cold PBS (pH 7.4), supplemented with protease inhibitor cocktail (Roche Diagnostics). All steps were conducted at $4^{\circ} \mathrm{C}$. The homogenized sample was first cleaned by centrifugation at $500 \times g$ for 10 minutes, and the supernatant was recentrifuged at $600 \times g$ for 10 minutes. Then, supernatant was further centrifuged at $3000 \times$ $g$ for 10 minutes and pellet was resuspended in $300 \mu \mathrm{L}$ of PBS buffer with protease inhibitors and centrifuged at 3000 $\times g$ for 10 minutes. This step was repeated twice. The final pellet, considered as nuclear fraction, was resuspended in PBS with protease inhibitors and stored at $-80^{\circ} \mathrm{C}$ until use. The cytosolic fraction was obtained by centrifugation of the first $3000 \times g$ supernatant at $15,000 \times g$ for 45 minutes. The resulting supernatant (considered as cytosolic fraction) was collected and stored at $-80^{\circ} \mathrm{C}$ for immunoblotting. Equal amounts of both fractions were subjected to immunoblot

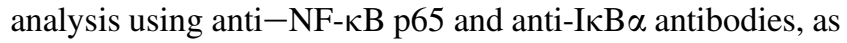
described below. Anti-lamin B1 and anti- $\beta$-actin antibodies were used as the loading control for nuclear and cytoplasmic proteins, respectively. Equal amounts of the cytoplasmic fraction with lamin B and the nuclear fraction with $\beta$-actin were used showing the specificity of the fractionation scheme (Supplemental Figure S2).

\section{Determination of ProCT, NPCT, and NF- $\kappa \mathrm{B}$ Proteins in Lungs}

Western blot analysis was performed as described previously. ${ }^{13,20}$ Briefly, equal amounts of protein $(50 \mu \mathrm{g})$ were subjected to electrophoresis on $4 \%$ to $20 \%$ SDS-PAGE gels (Bio-Rad Laboratories), depending on the size of the target proteins, and transferred onto a nitrocellulose membrane (Protran; Whatman GmbH, Dassel, Germany). Membranes were blocked with 5\% nonfat milk in Tris-buffered saline with Tween 20 buffer $[10 \mathrm{mmol} / \mathrm{L}$ Tris-HCl (pH 7.5), $150 \mathrm{mmol} / \mathrm{L}$ $\mathrm{NaCl}$, and $0.1 \%$ Tween 20 ] and incubated with primary antibodies for 2 hours at room temperature. Anti-NPCT antibody required 4 hours' incubation at room temperature. Membranes were hybridized with anti-NPCT antibody (1:2000; catalog number NB120-14817; Novus Biologicals, Littleton, CO), rabbit IKB $\alpha$ antibody (1:500; catalog number sc371; Santa Cruz Biotechnology, Santa Cruz, CA), and anti-NF-кB p65 antibody (1:500; catalog number sc372; Santa Cruz Biotechnology). After wash, blots were exposed to horseradish peroxidase-conjugated anti-rabbit (catalog number 31460) and anti-mouse (catalog number 31430) secondary antibodies (Thermo Fisher Scientific Inc., Waltham, MA) for 1 hour at room temperature, and immunoreactivities were visualized using an enhanced chemiluminescence Western blot analysis detection kit (Pierce, Rockford, IL). Blots were reprobed with anti- $\beta$-actin antibody (1:2000; catalog number ACTBD11B7; Santa Cruz Biotechnology]) and anti-lamin B1 antibody (1:500; catalog number 33-2000; Zymed, Carlsbad, CA) for normalization to equal protein loading. After scanning blots into a computer, individual bands were analyzed by PCBAS software version 2.08e (Raytest, Dusseldorf, Germany).

\section{Survival Study}

The survival study was performed in additional groups of animals. Anti-NPCT or control nonimmune $\operatorname{IgG}(n=20$ per group) was administered as described above. Twenty hours after CLP, the necrotic cecum was excised and the 
abdominal cavity was washed twice with $40 \mathrm{~mL}$ of warm, sterilized, normal saline solution. The abdominal incision was then closed in layers. The procedure of cecal excision in CLP animals was performed to mimic the clinical situation, in which the septic focus is removed whenever possible. The animals were then allowed food and water ad libitum and were monitored every 8 hours for the first 96 hours to record survival rate.

\section{Statistical Analysis}

Data were expressed as means \pm SEM. Statistical comparisons were performed using one-way analysis of variance, followed by the Student-Newman-Keuls test. Statistical differences between two groups were determined using the unpaired Student's $t$-test. Logarithmic $\left(\log _{10}\right)$ transformation of bacterial counts (CFUs/mL) was performed before statistical evaluation. Survival data were compared with a Kaplan-Meier curve and a log-rank test. $P<0.05$ was considered statistically significant.

\section{Results}

Immunoneutralization of Endogenous NPCT Reduces Sepsis-Induced CALCA Gene, ProCT, and NPCT Expression in Lungs

To evaluate whether NPCT is involved in CLP-induced lung inflammation, we determined levels of CALCA mRNA in lung tissues from CLP rats by RT-PCR. We also measured lung protein levels of ProCT and NPCT by Western blot analysis. The pulmonary levels of CALCA mRNA were increased approximately 4.3 -fold at 20 hours after CLP, compared with the levels in control shamoperated on groups (Figure 1A). Consistent with these results, levels of ProCT and NPCT protein were also significantly increased by 2.2- and 2.4-fold, respectively, after CLP (Figure 1B). Immunoneutralization of endogenous NPCT significantly decreased the pulmonary levels of CALCA mRNA, ProCT, and NPCT protein by $37 \%, 43 \%$, and $16 \%$, respectively, at 20 hours after CLP (Figure 1).

\section{Immunoneutralization of NPCT Attenuates Sepsis-Induced ALI}

To evaluate the protective effect of anti-NPCT on sepsisinduced lung damage, lung tissues were obtained to determine histopathological changes 20 hours after the CLP operation. We observed no histological alterations in lung specimens in the control sham-operated on group (Figure 2, $\mathrm{A}$ and D). There was a marked inflammatory response in lungs in the control CLP group, characterized by hemorrhage, alveolar congestion, thickening of alveolar wall/hyaline membrane formations, and infiltration and aggregation of PMNs in airspaces or vessel walls (Figure 2, B and E). However, these inflammatory alterations were markedly
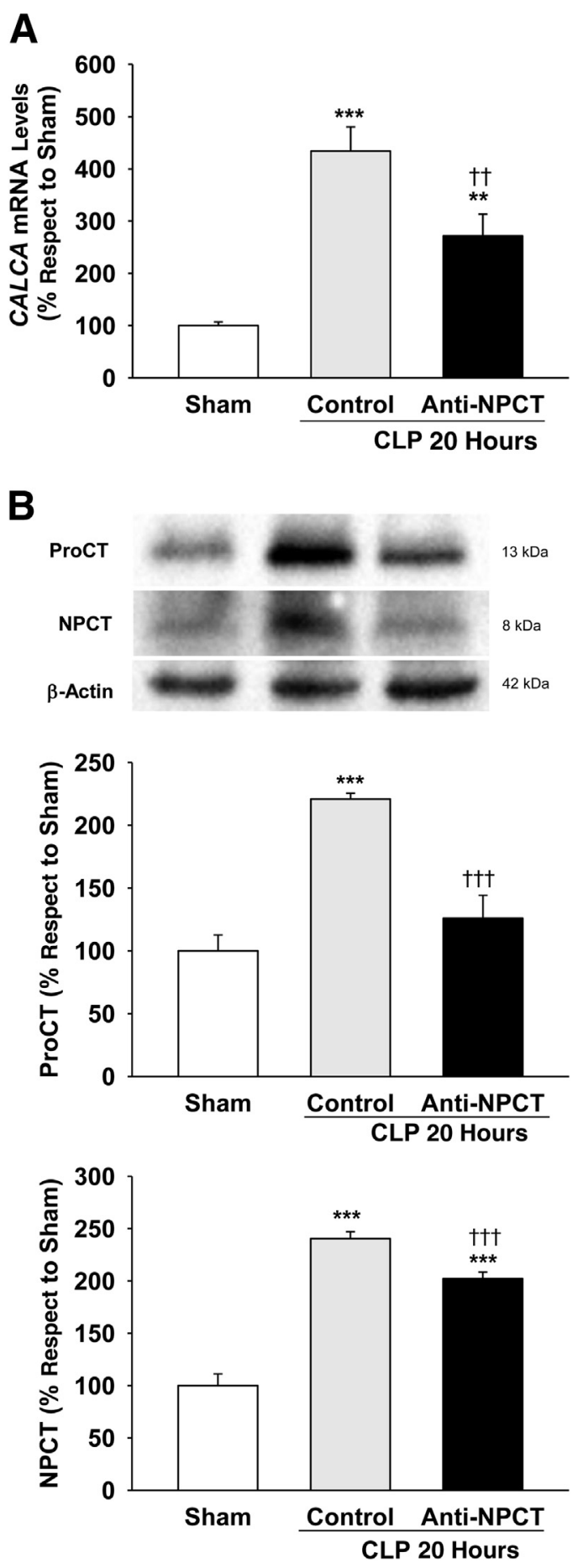

Figure 1 Immunoneutralization of aminoprocalcitonin (NPCT) reduces cecal ligation and puncture (CLP)-induced expression of CALCA, procalcitonin (ProCT), and NPCT in the lung tissues of the rats. Sepsis was induced in male Wistar rats after CLP. Sham-operated on animals underwent identical laparotomy but not CLP. Two hours after CLP, $200 \mu \mathrm{g} / \mathrm{kg}$ of anti-murine NPCT or control IgG was administered i.p., immediately followed by continuous i.p. infusion of $16 \mu \mathrm{g} /$ hour of the appropriate peptide via osmotic minipumps. Lung tissues were obtained 20 hours after CLP. A: Levels of CALCA mRNA in the lung tissues by real-time PCR using GAPDH as control. B: Western blot analysis of the expression of ProCT and NPCT in lung tissues. Anti- $\beta$-actin antibody was used as a loading control. Data are means \pm SEM from three independent experiments, which included 10 rats per treatment group. ${ }^{* \star} P<0.01,{ }^{* * *} P<0.001$ versus sham group; ${ }^{\dagger \dagger} P<0.01,{ }^{\dagger \dagger} P<0.001$ versus control group. 
attenuated in the anti-NPCT group (Figure 2, C and F). As expected, the lung water content (as measured by W/D weight ratios) in the CLP plus anti-NPCT group was significantly lower than those in the CLP group (Figure 2G). Moreover, there was no statistical significance in lung W/D weight ratio between the anti-NPCT plus CLP and shamoperated on group. Consistent with these findings, histological scores of lung tissue were significantly higher after the CLP procedure (Figure $2 \mathrm{H}$ ). MPO activity also paralleled the findings of the lung injury score (Figure 2I). MPO activity was low in the control sham-operated on group. Exposure to the CLP challenge resulted in a significant increase in lung MPO activity (2.8-fold). Anti-NPCT treatment significantly decreased MPO activity by $43 \%$. However, MPO activity was still significantly higher than that in sham-operated on animals (Figure 2I). As a result, neutralization of endogenous NPCT ameliorated lung histopathological features and reduced the severity of lung injury.

\section{Effects of Anti-NPCT Administration on Circulating} Neutrophils and Accumulation of Neutrophils into the Lung and Peritoneal Cavity

To independently verify the results of the MPO assay, the number of PMNs contained in each section of the individual rat lung was counted. The PMN numbers, assessed by direct counting (Figure 3A), support the MPO measurements. The number of PMNs in the lung tissues was increased approximately 5.5-fold at 20 hours after CLP, compared with the number of PMNs in control sham-operated on groups (Figure 3A). Anti-NPCT treatment significantly decreased the number of PMNs in lungs by $51 \%$, a decrease that agreed with our estimations of MPO activity. To assess whether NPCT contributed to PMN mobilization during the systemic inflammatory response induced by CLP, we next investigated the effect of anti-NPCT treatment on circulating PMN numbers and PMN recruitment into the peritoneum. The number of circulating PMNs was significantly decreased
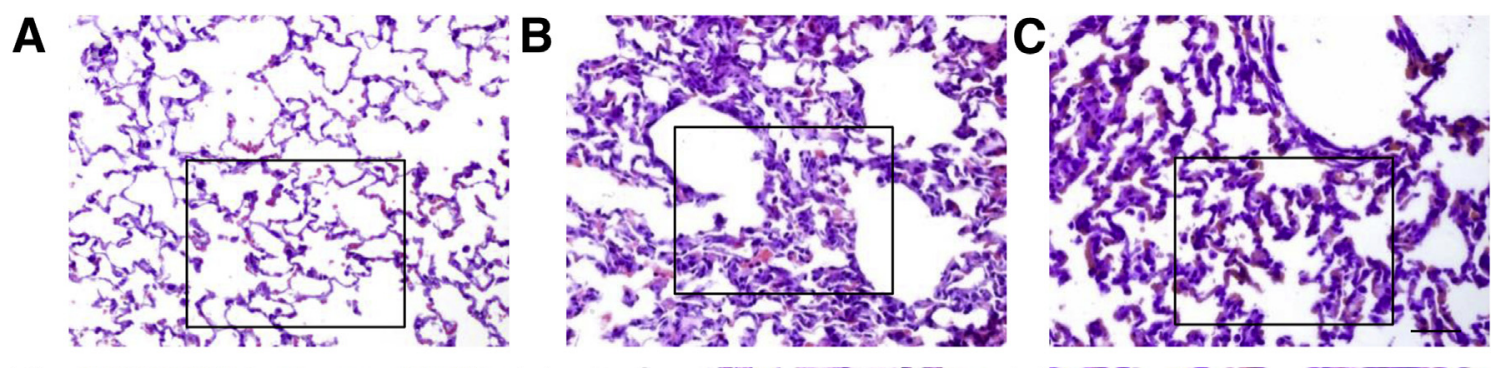

D
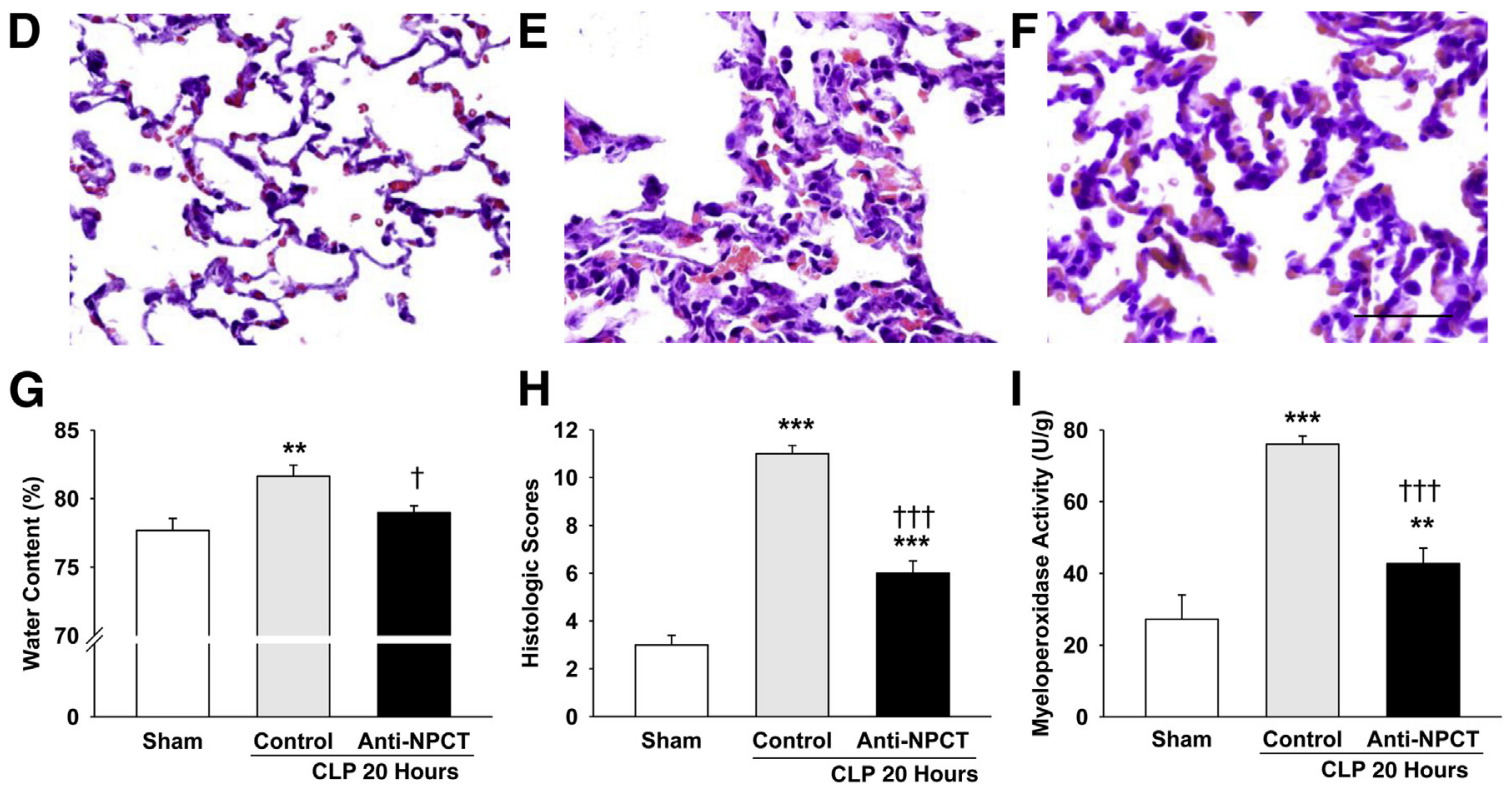

Figure 2 Inhibition of cecal ligation and puncture (CLP)-induced lung inflammation by anti-NPCT treatment. Photomicrograph of a pulmonary hematoxylin and eosin-stained section from a sham-operated on rat (A), 20 hours after CLP treated with control IgG (B), and 20 hours after CLP treated with anti-NPCT antibody (C). D-F: High-magnification images from the boxed areas in A-C, respectively. G: Alterations in lung water content in shamoperated on animals and rats treated with control IgG (Control) or anti-NPCT antibody 20 hours after CLP. Water content (lung edema) was determined by the W/D weight ratio. H: Lung injury score in sham-operated on animals and CLP-operated on animals treated with control IgG or anti-NPCT 20 hours after CLP. I: Changes in lung myeloperoxidase activity were measured as an index of lung PMN accumulation. Data are means \pm SEM from three independent experiments, which included 10 rats per treatment group. ${ }^{* *} P<0.01,{ }^{* * *} P<0.001$ versus sham group; ${ }^{\dagger} P<0.05,{ }^{\dagger \dagger \dagger} P<0.001$ versus control CLP group. Scale bar $=50 \mu \mathrm{m}(\mathbf{A}-\mathbf{F})$. 

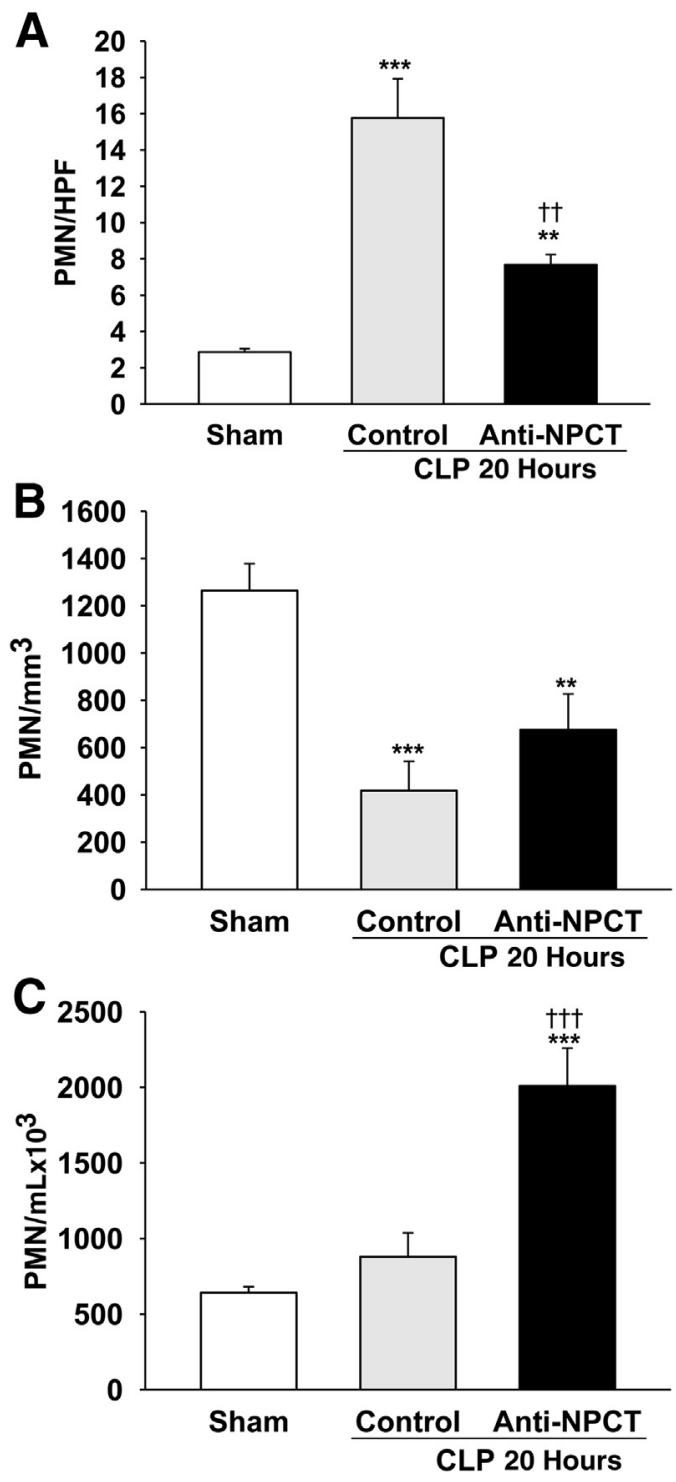

Figure 3 Immunoneutralization of aminoprocalcitonin (NPCT) reverses cecal ligation and puncture (CLP)-induced changes in the number of PMNs in lungs, blood, and peritoneal fluid. Lung (A), blood (B), and peritoneal (C) samples were collected from sham and CLP animals treated with IgG (Control) or anti-NPCT 20 hours after surgery. The number of PMNs was determined as described in Materials and Methods. Data are means \pm SEM from three independent experiments, which included 10 rats per treatment group. Data in $\mathbf{A}$ are expressed as number of polymorphonuclear neutrophils (PMN) per high-powered field (HPF). ${ }^{* *} P<0.01,{ }^{* * *} P<0.001$ versus sham group; ${ }^{\dagger \dagger} P<0.01,{ }^{\dagger \dagger} P<0.001$ versus control group.

after CLP (Figure 3B). Treatment with anti-NPCT increased circulating PMN levels by 1.6-fold compared with that observed in control IgG-treated rats after CLP; however, it was still significantly less than that in sham-operated on animals. The number of peritoneal PMNs was not significantly modified in control IgG-treated rats after CLP when compared with those of sham-operated on rats (Figure 3C). Treatment with anti-NPCT, however, increased the number of peritoneal neutrophils by 2.3-fold after CLP when compared with the control IgG-treated group (Figure 3C).
Additional experiments in CLP animals with vehicle (PBS) in the minipump demonstrate that there was no significant change in the number of peritoneal PMNs between vehicleand IgG-treated animals after CLP (PBS, $1170 \pm 253 \times 10^{3}$ cells versus $880 \pm 157 \times 10^{3}$ cells in IgG-treated animals; $n=10$ per group).

\section{Immunoneutralization of NPCT Decreases Bacterial Load in Peritoneal Fluid, Blood, and Lungs}

The CLP model is known to be associated with the development of bacteremia involving the presence of both aerobic and anaerobic bacteria in the blood. ${ }^{44} \mathrm{We}$ obtained blood, peritoneal, and pulmonary samples 20 hours after sham surgery or CLP in rats that were treated i.p. with control IgG or anti-NPCT antibody (infused immediately after surgery). For each group, we cultured samples of blood, peritoneal fluid, and pulmonary homogenates in vitro
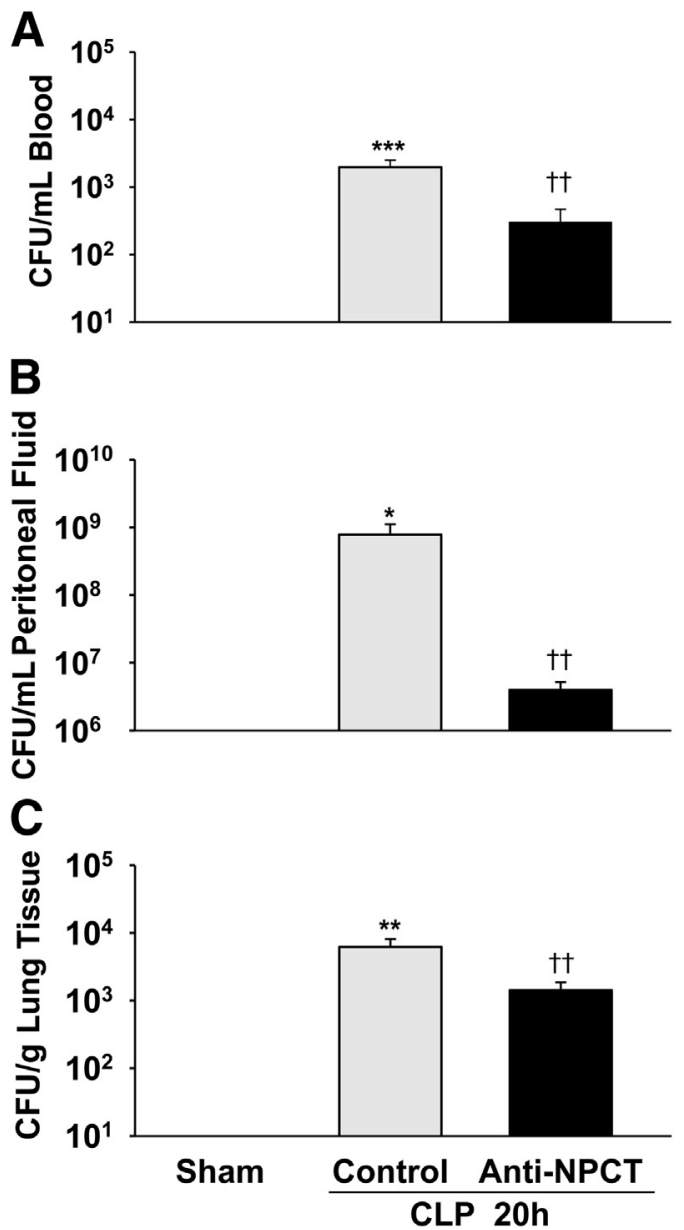

Figure 4 Immunoneutralization of aminoprocalcitonin (NPCT) reduces bacterial load. Alterations in bacterial load in blood (A), peritoneal fluid (B), and lungs (C) in sham-operated on animals and septic animals treated with nonimmune IgG (Control) or anti-NPCT 20 hours after cecal ligation and puncture (CLP). Colony forming units (CFU) data are expressed as CFU/ $\mathrm{mL}$ or CFU/g ( $\log _{10}$ scale) \pm SEM $(n=10)$ and compared by analysis of variance and the Student-Newman-Keuls method. ${ }^{*} P<0.05,{ }^{*} P<0.01$, and ${ }^{* * *} P<0.001$ versus sham group; ${ }^{\dagger \dagger} P<0.01$ versus control group. 
and determined the resulting bacterial CFUs (Figure 4, $\mathrm{A}-\mathrm{C}$, respectively). In the sham-operated on group, $\mathrm{CFUs}$ were not detectable. In contrast, CLP rats treated with control IgG had high CFU values, whereas in the CLP group treated with antibody against NPCT, the CFU value was significantly reduced compared with the respective control IgG-treated group.

\section{Effects of Anti-NPCT on Pulmonary Levels of Cytokines}

We investigated next the effects of anti-NPCT on the production of inflammatory mediators that are mechanistically linked to severe sepsis-induced lung injury. Pulmonary levels of TNF- $\alpha$, IL-6, IL-1 $\beta$, IL-10, and MIP-2 increased by 2.4-, 2.2-, 3.1-, 1.9-, and 4.3-fold, respectively, 20 hours after CLP (Figure 5, A-E). However, there was no significant difference in pulmonary RANTES levels between sham-operated on and CLP-operated on animals treated with control IgG (Figure 5F). Anti-NPCT treatment decreased the pulmonary levels of TNF- $\alpha$, IL-6, IL-1 $\beta$, MIP-2, and RANTES by $30 \%, 27 \%, 34 \%, 68 \%$, and $36 \%$, respectively, after CLP, and there was no significant difference in pulmonary TNF- $\alpha$, IL-6, IL-1 $\beta$, MIP-2, and RANTES levels between sham-operated on and CLP anti-NPCT-treated animals (Figure 5, A-F, respectively). However, in contrast to inflammatory mediators, anti-NPCT treatment increased the pulmonary levels of the anti-inflammatory cytokine IL- 10 by $24 \%$ after CLP compared with those in control IgG-treated animals (Figure 5D).
Anti-NPCT Inhibits Sepsis-Induced IкB $\alpha$ Degradation and Nuclear NF- $\kappa$ B Translocation in Lungs

To study whether anti-NPCT treatment has any effect on NF- $\kappa$ B pathway in the lungs, cytoplasmic and nuclear NF- $\kappa \mathrm{B}$ p65 expression and $\mathrm{I} \kappa \mathrm{B} \alpha$ degradation in the cytoplasm were determined 20 hours after CLP by using Western blot analysis. NF- $\kappa B$ p65 levels in the nucleus increased by 2.3 -fold after CLP, which was associated with a 1.9- and 1.7-fold decrease in the cytoplasmic levels of NF- $\kappa \mathrm{B}$ p 65 and $\mathrm{I} \kappa \mathrm{B} \alpha$, respectively (Figure 6). All these effects were significantly blocked by administration of anti-NPCT. Treatment with anti-NPCT resulted in a $46 \%$ decrease in the nuclear levels of NF- $\kappa \mathrm{B}$ p65 (Figure 6A) and a 30\% and 24\% increase in the cytoplasmic levels of $\mathrm{I} \kappa \mathrm{B} \alpha$ and NF- $\kappa \mathrm{B}$ p65, respectively (Figure 6B). These results indicate that anti-NPCT treatment prevents NF- $\kappa \mathrm{B}$ translocation in the lungs.

\section{Effects of Anti-NPCT Administration on Survival Rate}

After CLP, all animals develop bacteremia due to enteric organisms and death occurs in 100\% of animals (Figure 7). All sham-operated on rats without CLP survived. By 4 to 6 hours after CLP, all of the rats had developed the early clinical signs of sepsis, including lethargy, piloerection, and diarrhea. The survival rate after CLP with control IgG administration was $50 \%$ on day $1,40 \%$ on day 2 , and decreased to $0 \%$ on day 3 (Figure 7). Treatment with antiNPCT, however, improved the survival rate to $92 \%$ on
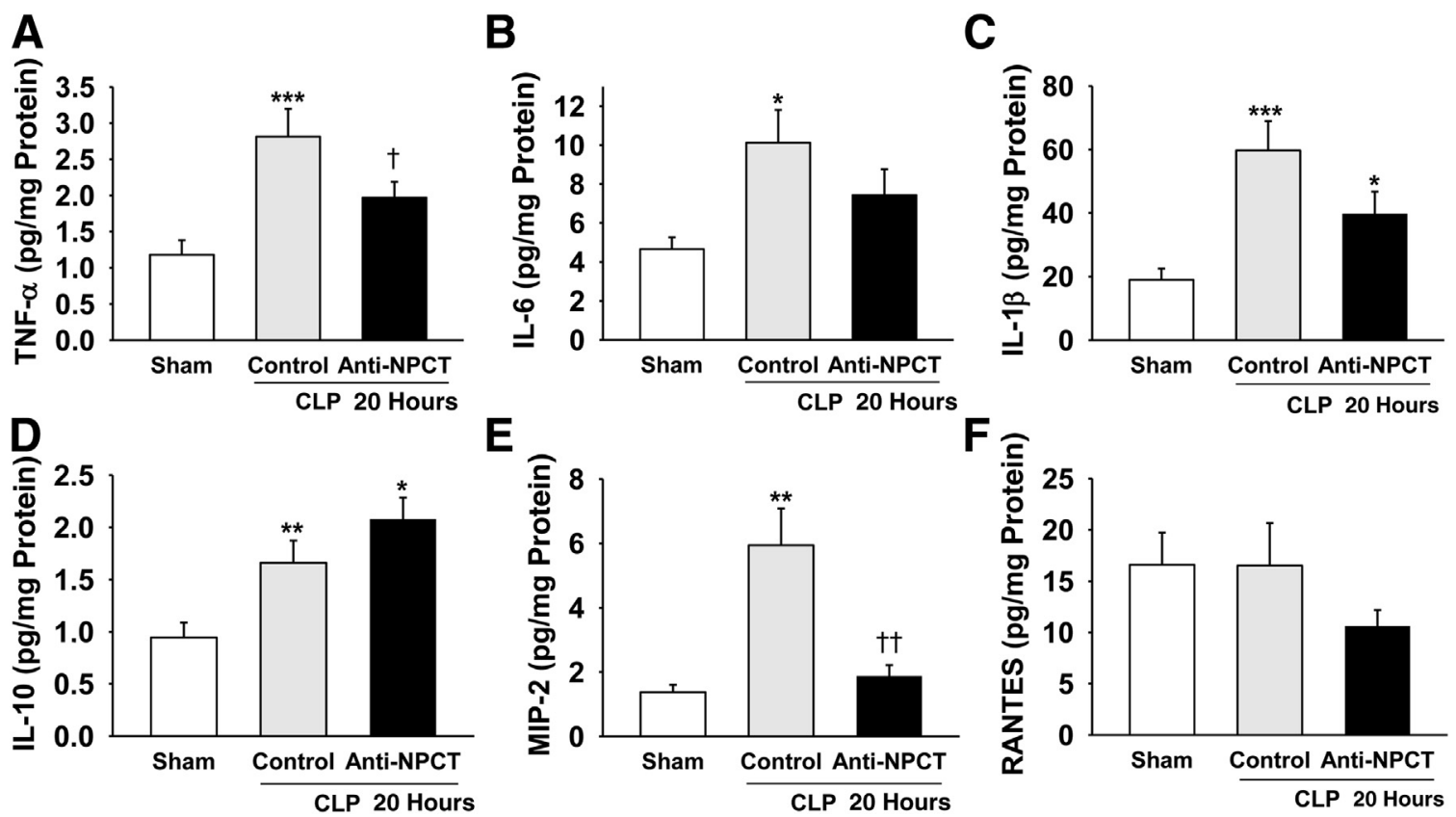

Figure 5 Immunoneutralization of aminoprocalcitonin (NPCT) reduces the pulmonary production of inflammatory cytokines in septic rats. Pulmonary levels of tumor necrosis factor (TNF)- $\alpha$ (A), IL-6 (B), IL-1 $\beta$ (C), IL-10 (D), macrophage inflammatory protein (MIP)-2 (E), and regulated on activation normal T cell expressed and secreted (RANTES; F) in sham-operated on animals and septic animals treated with IgG (Control) or anti-NPCT antibody 20 hours after cecal ligation and puncture (CLP) were determined in lung homogenates using a Luminex-based multiplex bead-array immunoassay. Data are means \pm SEM from three independent experiments, which included 10 rats per treatment group. ${ }^{\star} P<0.05$, ${ }^{* *} P<0.01$, and ${ }^{* * *} P<0.001$ versus sham group; ${ }^{\dagger} P<0.05$,

${ }^{\dagger \dagger} P<0.01$ versus control group. 

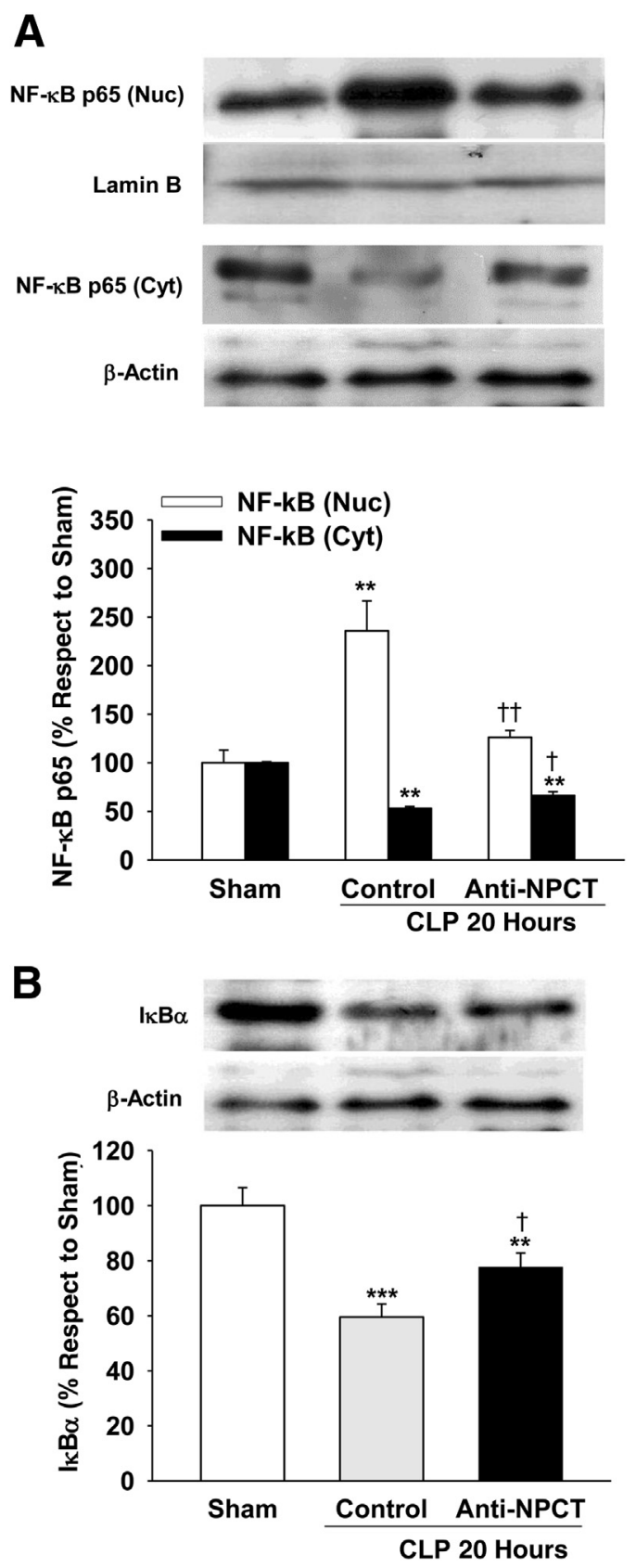

Figure 6 Immunoneutralization of aminoprocalcitonin (NPCT) inhibits $\mathrm{I} \kappa \mathrm{B} \alpha$ degradation and nuclear (Nuc) NF- $\mathrm{B}$ p 65 translocation in lung tissues of septic rats. Alterations in nuclear and cytoplasmic levels of NF- $\kappa B$ p65 (A) and cytoplasm levels of $\mathrm{I} \kappa \mathrm{B} \alpha(\mathbf{B})$ in the lungs in sham-operated on animals and septic animals treated with control IgG or anti-NPCT 20 hours after cecal ligation and puncture (CLP) were determined as described in Materials and Methods. Anti-lamin B1 and anti- $\beta$-actin antibodies were used as the loading control for nuclear and cytoplasmic proteins, respectively. Representative blots are also presented. Data are means \pm SEM from three independent experiments, which included 10 rats per treatment group. ${ }^{* *} P<0.01,{ }^{* *} P<0.001$ versus sham group; ${ }^{\dagger} P<0.05$, ${ }^{\dagger} P<0.01$ versus control group. Cyt, cytosolic.

days 1 to 2 and to $75 \%$ on day 3 . By day $4,67 \%$ of the rats survived (Figure 7), and there were no additional deaths in the next 6 days (Supplemental Figure S1). Furthermore, anti-NPCT treatment significantly attenuated the clinical manifestations of sepsis, such as lethargy, diarrhea, body weight loss, and hypothermia (not depicted).

\section{Discussion}

Despite the increased understanding of the complex pathophysiological features of sepsis and the discovery of new treatments, sepsis, when accompanied by ALI/ARDS, continues to be the leading cause of death in intensive care units. Molecular mechanisms of sepsis-induced inflammation and immune dysfunction remain largely unknown, hampering the development of therapeutics to treat this devastating disease.

SIRS/sepsis has been found to be associated with increased serum levels of gene products transcribed from the $C A L C A$ gene, including the prohormone ProCT and its aminoterminus peptide NPCT. In physiological conditions or in the absence of infection, CALCA transcription is restricted to neuroendocrine cells, mainly $\mathrm{C}$ cells of the thyroid, and mature CT is secreted into the bloodstream following a regulated pathway. Ubiquitous expression of CALCA in parenchymal tissues and elevated levels of circulating ProCT and NPCT have been shown in a variety of mammalian sepsis and endotoxemia models. ${ }^{28}$

Leukocytes, mainly peripheral blood mononuclear cells, macrophage-activated adipocytes, and endothelial cells, are potentially capable of contributing to the in vivo extrathyroidal ProCT production and may contribute to the marked increase in circulating ProCT and NPCT by recruiting parenchymal cells within the infected tissue. $^{30,31,45}$ Although its usefulness as a harmful biomarker

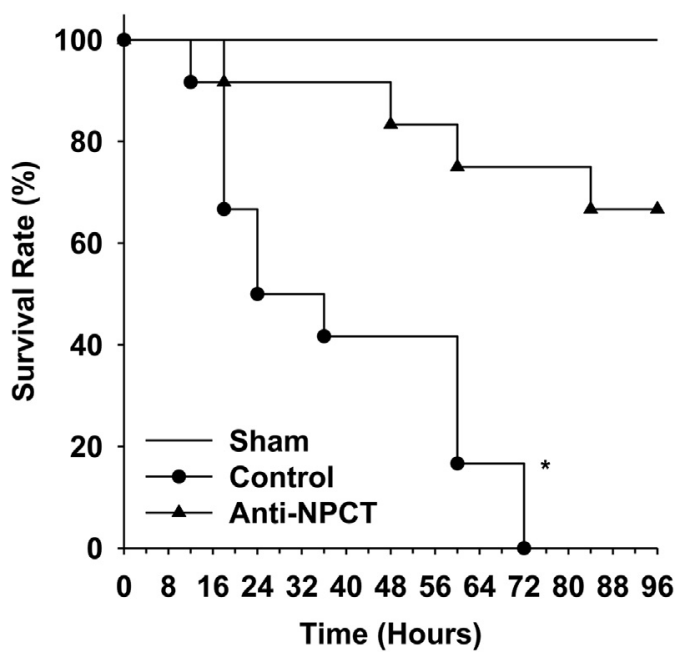

Figure 7 Immunoneutralization of aminoprocalcitonin (NPCT) improves survival after severe sepsis. Survival rate 96 hours after cecal ligation and puncture (CLP) and cecal excision with control IgG treatment (solid circles) and CLP with anti-NPCT treatment (solid triangles). Two hours after CLP, $200 \mu \mathrm{g} / \mathrm{kg}$ of anti-murine NPCT or control IgG was administered i.p., immediately followed by continuous i.p. infusion of $16 \mu \mathrm{g} / \mathrm{hour}$ of the appropriate antibody via a minipump. There were 20 animals in each group. The survival rate was estimated by the Kaplan-Meier method and compared by log-rank test. ${ }^{*} P<0.05$ versus CLP animals treated with control IgG. 
of sepsis is widely accepted ${ }^{46,47}$ and it has been suggested that the proinflammatory effects of ProCT and NPCT may be related to its action on CALCR/CALCRL, ${ }^{19,20}$ the exact role and function of ProCT as a mediator of the inflammatory response is still debated. ${ }^{29,48}$ Furthermore, the physiological significance of $C A L C A$ gene in sepsis is unclear.

A recent report demonstrates that deletion of the CALCA gene does not affect the outcome of severe infections in mice, ${ }^{49}$ which suggests that ProCT does not serve as a harmful biomarker and a therapeutic target of systemic inflammation and sepsis. ${ }^{29}$ Even if one assumes that the knockout mouse model has compensatory changes, the significance of this study is limited by the fact that ProCT transcripts were not expressed in nonneuroendocrine thyroidal tissues of control wild-type mice during infection and systemic inflammation, an observation different from all studies performed in mammals, including hamsters, ${ }^{28,50}$ rats, ${ }^{13}$ pigs, ${ }^{45,51}$ dogs,${ }^{52}$ primates, ${ }^{53}$ and humans. ${ }^{54}$ Furthermore, expression of tissue ProCT transcripts and serum cytokines was only performed in wildtype mice challenged with a sublethal dose of endotoxin. Thus, in agreement with authors, this is not an ideal lossof-function model to test the role of CALCA gene in the pathogenesis of sepsis.

Recent research indicates that NPCT is actively involved in the systemic inflammatory response and the progression of sepsis. Administration of NPCT induced septic-like responses (eg, fever, anorexia, and body loss weight), ${ }^{33-35}$ and immunoneutralization with monoclonal and specific polyclonal antibodies that are reactive to NPCT significantly improves survival and pathophysiological parameters in a rat model of lethal endotoxemia. ${ }^{13}$ These findings suggest that NPCT may be a mediator of severe sepsis-induced organ injury and that immunotherapy against NPCT may be an effective treatment for severe sepsis.

In contrast to the overwhelming endotoxemia models in which the lethal cytokinemia is responsible for the death of animals, bacterial invasion and outgrowth in the host organs is responsible for lethality in infection with live microorganisms. CLP in rodents has become the most widely used model for experimental sepsis and is currently considered as the gold standard in sepsis research. ${ }^{36}$ Perforation of the cecum results in bacterial peritonitis, which is followed by translocation of mixed enteric bacteria into the blood compartment. At the onset of sepsis, bacteremia then triggers systemic activation of the inflammatory response, subsequent septic shock, multiorgan dysfunction, and, finally, death. ${ }^{37}$ Therefore, we used a lethal model of acute sepsis induced in rats by CLP to assess the pathophysiological role of NPCT in sepsis-induced ALI and mortality.

Our present study shows that lung injuries, characterized by increased lung water content, disruption of lung architecture, extravasation of red blood cells, and accumulation of inflammatory cells, are present 20 hours after CLP. These injuries are associated with increased levels of CALCA mRNA and the propeptide ProCT in the pulmonary tissues. We also found that pulmonary levels of NPCT 20 hours after CLP in control-treated animals were $150 \%$ higher than those in sham-operated on animals. Immunoneutralization of endogenous NPCT significantly inhibited all these effects. The decrease in pulmonary levels of NPCT is associated with mitigated lung injury, decreased pulmonary bacterial load and recruitment of neutrophils, and improved survival after CLP. These findings suggest that sustained CALCA expression, ProCT production, and subsequent release of NPCT play a relevant role in ALI secondary to sepsis. Moreover, the fact that administration of anti-NPCT inhibits its own expression suggests an indirect effect, because inhibiting function would be expected to lead to a compensatory response in $C A L C A$ expression.

A limitation of this study is that NPCT is an integral component of ProCT, and one cannot neutralize NPCT without appreciable neutralizing ProCT. Furthermore, procedures used in this study do not distinguish between antibody-bound (presumably inactive) NPCT and free NPCT. However, present findings confirm the notion about the pathophysiological role of $C A L C A$ gene products in severe sepsis. Moreover, the fact that administration of antiNPCT antibody increased the 10-day survival rate after CLP confirms this notion.

Widespread destruction of alveolar epithelium and increased lung vascular permeability, alveolar hemorrhage, PMN infiltration, and severe histological damage represent the typical lesion in ALI. ${ }^{7,55}$ Our studies showed that anti-NPCT therapy attenuated these histopathological consequences of ALI, including pulmonary distortion, hemorrhage, edema, and recruitment of PMNs in lungs of rats with CLP. Excessive activation and migration of neutrophils into the lung is a hallmark of ALI. Neutrophils are important contributors to the progression of ALI/ARDS, and higher neutrophil concentration in the bronchoalveolar lavage fluid of patients with ARDS is often associated with greater severity of the disease. ${ }^{8} \mathrm{We}$ found a significant reduction in the number and infiltration of PMNs in lungs after antiNPCT. These findings suggest that the enhanced pulmonary concentrations of NPCT in the setting of sepsis may contribute to PMN accumulation in the lungs and localized inflammatory injury. On the basis of histological evaluation, the lung injury score also significantly decreased with the administration of anti-NPCT. These findings suggest that anti-NPCT might exert a salutary effect on the integrity of the alveolocapillary membrane, thereby markedly improving lung morphological features and the excessive influx of inflammatory cells into the lung tissue.

Neutrophils play an important role in limiting the expansion and dissemination of bacteria and represent the body's first line of defense, and PMN migration to the site of infection is important in the control of infection in sepsis. The change in PMN count in peripheral blood is another important parameter in sepsis. ${ }^{56}$ Herein, we have shown that although the increase in circulating PMNs was not significant in CLP rats compared with sham-operated on animals, treatment with anti-NPCT caused a significant increase in 
PMN count 24 hours after CLP. These results suggest that the beneficial effect of anti-NPCT treatment on survival rate may be related with high levels of circulating PMNs. An improvement in the recruitment and function of PMNs could lead to a reduced mortality due to sepsis. We also found that anti-NPCT treatment increased PMN recruitment into the peritoneum after CLP. Because PMNs play a key role in the elimination of invading microorganisms, an important mechanism of host defense is PMN influx into the peritoneum, which represents the local site of inflammation in this CLP model of severe sepsis. These findings suggest that neutralization of NPCT leads to heightened inflammatory responses in the peritoneum, which thereby limit invasion of bacteria and mobilization of neutrophils out of the circulation into the lungs.

Consistently, anti-NPCT treatment decreased bacterial load in blood, peritoneum, and lung tissues after CLP. This could be due to the general improvement in the animals' condition, thereby leading to increased bacterial phagocytosis by macrophages and neutrophils. Taken together, these results suggest that NPCT has a proinflammatory role in CLP-induced sepsis and that the beneficial effects of antiNPCT in sepsis-induced ALI could be mediated through compartmentalization of the host inflammatory response, infection to the peritoneum, and a decrease in remote exposures to infection. However, the precise mechanisms responsible for the effect of anti-NPCT on bacterial load warrant further investigation. In this regard, we incubated subcultures of mixed aerobic or anaerobic bacteria obtained from the blood of CLP rats in the presence of either control IgG or anti-NPCT antibody; there was no reduction in CFU values (data not shown), indicating that antibody against NPCT is not directly bacteriostatic.

Proinflammatory cytokines, such as TNF- $\alpha$, IL- $1 \beta$, and IL-6, are considered pivotal mediators for initiating, amplifying, and perpetuating sepsis-induced lung injury. ${ }^{9,57}$ These cytokines mediate the adhesive properties of phagocytic cells, vascular dysfunction, recruitment of leukocytes, and tissue damage, and/or they potentiate death during sepsis. ${ }^{11,49}$ We have previously shown that neutralization of NPCT improved survival of rats in a model of lethal endotoxemia by down-regulating the overproduction of circulating levels of TNF- $\alpha$ and IL-1 $\beta .^{13}$ To determine whether these mediators are associated with the protective effect of anti-NPCT on sepsis-induced lung inflammation, we examined the pulmonary levels of TNF- $\alpha$, IL- $1 \beta$, and IL- 6 . In this regard, the fact that anti-NPCT down-regulated pulmonary levels of TNF- $\alpha$, IL-1 $\beta$, and IL-6 in septic animals suggests another possible mechanism by which anti-NPCT exerts a beneficial effect in severe sepsis-induced ALI. These results also suggest an important role of NPCT in the regulation of cytokine responses during severe sepsis.

The anti-inflammatory effect of anti-NPCT was confirmed by the result showing that anti-NPCT increased pulmonary levels of IL-10. The increased production of anti-inflammatory mediators, especially IL-10, observed in inflammation and sepsis occurs in parallel with massive production of proinflammatory cytokines. ${ }^{58} \mathrm{IL}-10$ is a pleiotropic cytokine that is produced by activated monocytes, macrophages, $\mathrm{T}$ helper cells, and B cells. IL-10 reduces TNF- $\alpha$, IL- 6 , and MIP-2 production. ${ }^{59,60}$ IL-10 also inhibits NF- $\kappa$ B activation by preventing degradation of the NF- $\kappa \mathrm{B}$ inhibitory protein, $\mathrm{I} \kappa \mathrm{B} \alpha{ }^{61}$ In animal models of sepsis, neutralization of IL-10 resulted in exaggerated proinflammatory cytokine expression, accumulation of inflammatory cells in the lung, and death, whereas administration of recombinant IL-10 conferred significant therapeutic protection. ${ }^{62,63}$ Our previous study has shown that i.p. administration of anti-NPCT improves long-term survival and increased circulating levels of IL-10 in a rat model of lethal endotoxemia. ${ }^{13}$ The results from the present study provide further evidence about the proinflammatory role of NPCT in severe sepsis, showing that its immunoneutralization increases the production of IL-10 in lung tissues. This result suggests another possible mechanism by which anti-NPCT exerts a beneficial effect in sepsis-induced ALI and mortality.

Chemokines also play a central role in mediating the signaling cascade that targets PMN to sites of infection and inflammation. ${ }^{10}$ MIP-2 and RANTES, produced by macrophages, are essential for PMN and monocyte recruitment into lung tissue and are associated with lung injury and mortality after sepsis.

MIP-2 is essential for early PMN recruitment and plays a major role in mediating the neutrophilic inflammatory response of the rodent lung. The increase in lung MIP-2 levels correlated with the accumulation of PMN, lung injury, and mortality after CLP. ${ }^{64}$ Furthermore, neutralization of MIP-2 inhibited PMN accumulation within the lung and reduced vascular leakage in rats treated with endotoxin. ${ }^{65}$ Our results show that the basal levels of MIP-2 in the lungs were low, increased after CLP challenge, and were blocked significantly by anti-NPCT.

Histological examination of the lungs and lung MPO activity confirm reduced PMN infiltration. Furthermore, neutralization with anti-NPCT decreased the pulmonary levels of RANTES, a chemokine associated with macrophage recruitment to the lungs during endotoxemia. ${ }^{66}$ The fact that anti-NPCT reduced pulmonary levels of MIP-2 and RANTES partially explains the absence of inflammatory infiltrates in the lungs. Consistently, it has been shown that NPCT induces leukocyte chemotaxis and endotoxin-induced CD11b up-regulation in activated monocytes and PMNs. ${ }^{67}$ Together, these data suggest that the anti-NPCT antibody is interfering directly or indirectly with the recruitment and activation of inflammatory cells. They also suggest that the increased pulmonary concentrations of NPCT present during severe sepsis contribute to the accumulation of PMNs in the lungs through enhancing chemotaxis via chemokines and other proinflammatory mediators. Thus, potential therapeutic target sites of anti-NPCT include local control of the response of the lung to systemic inflammation, as well as direct and/or indirect modulation of neutrophil migration and activation. This is concomitant with a reduced production of 
proinflammatory mediators in lung tissues, attenuating organ damage and increasing survival.

Expression of proinflammatory genes involved in the pathogenesis of sepsis is regulated by transcriptional factors. In this regard, NF- $\kappa \mathrm{B}$ appears to play a central role in the development of pulmonary inflammation and ALI. ${ }^{6}$ Under unstimulated conditions, NF- $\kappa \mathrm{B}$ p65 is present in the cytosol and is bound to inhibitory protein I $\mathrm{I} B \alpha{ }^{68}$ However, in inflammation and sepsis, NF- $\kappa \mathrm{B}$ is translocated into the nucleus to drive expression of a variety of inflammatory genes, which are involved in the pathogenesis of ALI. ${ }^{68}$ Increased activation of NF- $\kappa \mathrm{B}$ is found in airway endothelial cells, lung alveolar epithelial cells, PMNs, and macrophages from patients with sepsis. ${ }^{7,69}$ In vivo studies demonstrated that suppression of lung NF- $\kappa \mathrm{B}$ activation results in decreased proinflammatory mediator expression and reduced inflammatory injury. ${ }^{69}$ The results from the present study provide in vivo evidence showing that antiNPCT inhibits sepsis-induced $\mathrm{I} \kappa \mathrm{B} \alpha$ degradation and $\mathrm{NF}-\kappa \mathrm{B}$ nuclear translocation in the lungs. Although these findings suggest that NPCT promotes NF- $\kappa \mathrm{B}$ activation and the molecular mechanisms and cellular targets leading to inhibition of NF- $\mathrm{BB}$ activation by anti-NPCT remain to be determined, our study has shed some light on this issue.

A limitation of our study is that it was focused on the 20 hours after CLP, and the question as to whether anti-NPCT posts similar beneficial effects at other times remains to be investigated. Because severe sepsis occurred at 20 hours after CLP ${ }^{38}$ we chose this time point to assess lung injury. The selection of a fulminant variant of the CLP model was directed at studying late resting-inflammatory phase (20 hours after CLP) and the potential contribution of endogenous NPCT to the outcome from CLP and not early events associated with the response to sepsis in a relatively short time period. Another shortcoming of our study is that many cells, including endothelial cells, neutrophils, and monocytes, are responsible for the expression of inflammatory mediators, including ProCT. Future research should, therefore, be performed to clarify which cells participate in antiNPCT's observed effects on sepsis-induced ALI.

In summary, immunoneutralization of NPCT significantly attenuated the CLP-induced lung injuries, with a significantly increased survival rate of the septic animals. AntiNPCT amelioration of CLP-induced ALI involved a decrease in the lung W/D weight ratio, bacterial load, and inflammatory PMN infiltration into lung tissue, which ameliorates lung histopathological features and alleviates pulmonary edema. The beneficial effect of anti-NPCT on lung injury also involved inhibition of $\mathrm{I} \kappa \mathrm{B} \alpha / \mathrm{NF}-\kappa \mathrm{B}$ pathway and suppression of proinflammatory cytokine production. Anti-NPCT also increased the expression of IL-10, which is known to play a protective role in lung inflammation. Taken together, our results suggest that the beneficial effects on cytokine expression, NF- $\kappa \mathrm{B}$ activation, and lung inflammation and injury are all downstream of less bacterial invasion and outgrowth in the host organs responsible for lethality in infection. Although more studies are needed to fully clarify the potential role of NPCT in sepsis and the pathogenic events that lead to development of multiple organ failure, our results suggest that NPCT is a potentially useful target that provides new strategy in clinical prevention and treatment of ALI/ARDS in sepsis.

\section{Acknowledgments}

We thank Dr. Ana Maria Garcia for real-time PCR analysis of lung tissues and José Córdoba (Valme University Hospital, Seville, Spain) for help with the bacterial load experiments.

\section{Supplemental Data}

Supplemental material for this article can be found at http://dx.doi.org/10.1016/j.ajpath.2014.07.025.

\section{References}

1. Riedemann NC, Guo RF, Ward PA: The enigma of sepsis. J Clin Invest 2003, 112:460-467

2. Hotchkiss RS, Karl IE: The pathophysiology and treatment of sepsis. N Engl J Med 2003, 348:138-150

3. Rubenfeld GD, Caldwell E, Peabody E, Weaver J, Martin DP, Neff M, Stern EJ, Hudson LD: Incidence and outcomes of acute lung injury. N Engl J Med 2005, 353:1685-1693

4. Maybauer MO, Maybauer DM, Herndon DN: Incidence and outcomes of acute lung injury. N Engl J Med 2006, 354:416-417

5. Matthay MA, Zemans RL: The acute respiratory distress syndrome: pathogenesis and treatment. Annu Rev Pathol 2011, 6:147-163

6. Abraham E: NF-kappaB activation. Crit Care Med 2000, 28: N100-N104

7. Yang KY, Arcaroli JJ, Abraham E: Early alterations in neutrophil activation are associated with outcome in acute lung injury. Am J Respir Crit Care Med 2003, 167:1567-1574

8. Grommes J, Soehnlein O: Contribution of neutrophils to acute lung injury. Mol Med 2011, 17:293-307

9. Goodman RB, Pugin J, Lee JS, Matthay MA: Cytokine-mediated inflammation in acute lung injury. Cytokine Growth Factor Rev 2003, 14:523-535

10. Bhatia M, Zemans RL, Jeyaseelan S: Role of chemokines in the pathogenesis of acute lung injury. Am J Respir Cell Mol Biol 2012, 46:566-572

11. Yoshidome H, Kato A, Edwards MJ, Lentsch AB: Interleukin-10 inhibits pulmonary NF-kB activation and lung injury induced by hepatic ischemia-reperfusion. Am J Physiol Lung Cell Mol Physiol 1999, 277:L919-L923

12. Latifi SQ, O'Riordan MA, Levine AD: Interleukin-10 controls the onset of irreversible shock. Infect Immun 2002, 70:4441-4446

13. Tavares E, Miñano FJ: Immunoneutralization of the aminoprocalcitonin peptide of procalcitonin protects rats from lethal endotoxaemia: neuroendocrine and systemic studies. Clin Sci (Lond) 2010, 119:519-534

14. Roos BA, Okano K, Deftos LJ: Evidence for a pro-calcitonin. Biochem Biophys Res Commun 1974, 60:1134-1140

15. Poyner DR, Sexton PM, Marshall I, Smith DM, Quirion R, Born W, Muff R, Fischer JA, Foord SM: International Union of Pharmacology, XXXII: the mammalian calcitonin gene-related peptides, adrenomedullin, amylin, and calcitonin receptors. Pharmacol Rev 2002, 54: 233-246 
16. Steenbergh PH, Hoppener JW, Zandberg J, Visser A, Lips CJ, Jansz HS: Structure and expression of the human calcitonin/CGRP genes. FEBS Lett 1986, 209:97-103

17. Le Moullec JM, Jullienne A, Chenais J, Lasmoles F, Guliana JM, Milhaud G, Moukhtar MS: The complete sequence of human preprocalcitonin. FEBS Lett 1984, 167:93-97

18. Goltzman D, Mitchell J: Interaction of calcitonin and calcitonin generelated peptide at receptor sites in target tissues. Science 1985, 227 : $1343-1345$

19. Sexton PM, Christopoulos G, Christopoulos A, Nylen ES, Snider RH, Becker KL: Procalcitonin has bioactivity at calcitonin receptor family complexes: potential mediator implications in sepsis. Crit Care Med 2008, 36:1637-1640

20. Tavares E, Maldonado R, Miñano FJ: Aminoprocalcitonin-mediated suppression of feeding involves the hypothalamic melanocortin system. Am J Physiol Endocrinol Metab 2013, 304: E1251-E1262

21. Russwurm S, Wiederhold M, Oberhoffer M, Stonans I, Zipfel PF, Reinhart K: Molecular aspects and natural source of procalcitonin. Clin Chem Lab Med 1999, 37:787-797

22. Conlon JM, Grimelius L, Thim L: Structural characterization of a high molecular-mass form of calcitonin [procalcitonin-(60-116)peptide] and its corresponding $\mathrm{N}$-terminal flanking peptide [procalcitonin-(1-57)-peptide] in a human medullary thyroid carcinoma. Biochem J 1988, 256:245-250

23. Burns DM, Forstrom JM, Friday KE, Howard GA, Roos BA: Procalcitonin's amino-terminal cleavage peptide is a bone-cell mitogen. Proc Natl Acad Sci U S A 1989, 86:9519-9523

24. Born W, Beglinger C, Fischer JA: Diagnostic relevance of the aminoterminal cleavage peptide of procalcitonin (PAS-57), calcitonin and calcitonin gene-related peptide in medullary thyroid carcinoma patients. Regul Pept 1991, 32:311-319

25. Snider RH, Nylén ES, Becker KL: Procalcitonin and its component peptides in systemic inflammation: immunochemical characterization. J Investig Med 1997, 45:552-560

26. Cotoi OS, Manjer J, Hedblad B, Engström G, Melander O, Schiopu A: Plasma procalcitonin is associated with all-cause and cancer mortality in apparently healthy men: a prospective populationbased study. BMC Med 2013, 11:180

27. Becker KL, Nylén ES, White JC, Müller B, Snider RH: Procalcitonin and the calcitonin gene family of peptides in inflammation, infection, and sepsis: a journey from calcitonin back to its precursors. J Clin Endocrinol Metab 2004, 89:1512-1525

28. Müller B, White JC, Nylén ES, Snider RH, Becker KL, Habener JF: Ubiquitous expression of the calcitonin-I gene in multiple tissues in response to sepsis. J Clin Endocrinol Metab 2001, 86:396-404

29. Becker KL, Snider R, Nylen ES: Procalcitonin in sepsis and systemic inflammation: a harmful biomarker and a therapeutic target. Br J Pharmacol 2010, 159:253-264

30. Oberhoffer M, Stonans I, Russwurm S, Stonane E, Vogelsang H, Junker U, Jager L, Reinhart K: Procalcitonin expression in human peripheral blood mononuclear cells and its modulation by lipopolysaccharides and sepsis-related cytokines in vitro. J Lab Clin Med 1999, 134:49-55

31. Linscheid P, Seboek D, Schaer DJ, Zulewski H, Keller U, Müller B: Expression and secretion of procalcitonin and calcitonin gene-related peptide by adherent monocytes and by macrophage-activated adipocyte. Crit Care Med 2004, 32:1715-1721

32. Ojeda ML, Ambrosiani J, Maldonado R, Tavares E, Miñano FJ: Identification and localization of procalcitonin-like immunoreactivity in the rat hypothalamus. Neurosci Lett 2006, 408:40-45

33. Tavares E, Maldonado R, Miñano FJ: N-procalcitonin: central effects on feeding and energy homeostasis in rats. Endocrinology 2007, 148: 1891-1901

34. Tavares E, Miñano FJ: Procalcitonin N-terminal peptide causes catabolic effects via the hypothalamus and prostaglandin-dependent pathways. Neuroendocrinology 2008, 88:316-326
35. Tavares E, Maldonado R, Garcia-Martinez A, Miñano FJ: Central administration of aminoprocalcitonin inhibits food intake and stimulates the hypothalamic-pituitary-adrenal axis in rats via the corticotrophin-releasing factor system. J Neuroendocrinol 2012, 24: $1040-1054$

36. Hubbard WJ, Choudhry M, Schwacha MG, Kerby JD, Rue LW 3rd, Bland KI, Chaudry IH: Cecal ligation and puncture. Shock 2005, 24(Suppl 1):52-57

37. Rittirsch D, Huber-Lang MS, Flierl MA, Ward PA: Immunodesign of experimental sepsis by cecal ligation and puncture. Nat Protoc 2009, $4: 31-36$

38. Baker CC, Chaudry IH, Gaines HO, Baue AE: Evaluation of factors affecting mortality rate after sepsis in a murine cecal ligation and puncture model. Surgery 1983, 94:331-335

39. Gonzalez-Rey E, Chorny A, Robledo G, Delgado M: Cortistatin, a new antiinflammatory peptide with therapeutic effect on lethal endotoxemia. J Exp Med 2006, 203:563-571

40. Bachofen M, Weibel ER: Structural alterations of lung parenchyma in the adult respiratory distress syndrome. Clin Chest Med 1982, 3:35-56

41. Tavares E, Miñano FJ, Maldonado R, Dascombe MJ: Endotoxin fever in granulocytopenic rats: evidence that brain cyclooxygenase- 2 is more important than circulating prostaglandin $\mathrm{E}(2)$. J Leukoc Biol 2006, 80:1375-1387

42. Gonzalez-Rey E, Chorny A, Robledo G, Delgado M: Urocortin and adrenomedullin prevent lethal endotoxemia by downregulating the inflammatory response. Am J Pathol 2006, 168:1921-1930

43. Gavilán MP, Castaño A, Torres M, Portavella M, Caballero C, Jiménez S, García-Martínez A, Parrado J, Vitorica J, Ruano D: Agerelated increase in the immunoproteasome content in rat hippocampus: molecular and functional aspects. J Neurochem 2009, 108: $260-272$

44. Deitch EA: Animal models of sepsis and shock: a review and lessons learned. Shock 1997, 9:1-11

45. Zannoni A, Giunti M, Bernardini C, Gentilini F, Zaniboni A, Bacci ML, Forni M: Procalcitonin gene expression after LPS stimulation in the porcine animal model. Res Vet Sci 2012, 93:921-927

46. Schneider HG, Lam QT: Procalcitonin for the clinical laboratory: a review. Pathology 2007, 39:383-390

47. Becker KL, Snider R, Nylen ES: Procalcitonin assay in systemic inflammation, infection, and sepsis: clinical utility and limitations. Crit Care Med 2008, 36:941-952

48. Braithwaite SS: Procalcitonin: marker, or mediator? Crit Care Med 1998, 26:977-978

49. Tuvim MJ, Clement CG, Huang ES, Cote GJ, Evans SE, Lei X, Deftos LJ, Gagel RF, Dickey BF: Deletion of the gene encoding calcitonin and calcitonin gene-related peptide $\alpha$ does not affect the outcome of severe infection in mice. Am J Respir Cell Mol Biol 2013, 49:151-155

50. Domenech V, Nylen E, White J, Snider R, Becker K, Landmann R, Müller B: Calcitonin gene-related peptide expression in sepsis: postulation of microbial infection-specific response elements within the calcitonin I gene promoter. J Investig Med 2001, 49:514-521

51. Becker KL, Nylen ES, Snider RH, Muller B, White JC: Immunoneutralization of procalcitonin as therapy of sepsis. J Endotoxin Res 2003, 9:367-374

52. Giunti M, Peli A, Battilani M, Zacchini S, Militerno G, Otto CM: Evaluation of CALC-I gene (CALCA) expression in tissues of dogs with signs of the systemic inflammatory response syndrome. J Vet Emerg Crit Care (San Antonio) 2010, 20:523-527

53. Morgenthaler NG, Struck J, Chancerelle Y, Weglhner W, Agay D, Bohuon C, Suarez-Domenech V, Bergmann A, Müller B: Production of procalcitonin [ProCT] in non thyroidal tissue after LPS injection. Horm Metab Res 2003, 35:290-295

54. Linscheid P, Seboek D, Nylen ES, Langer I, Schlatter M, Becker KL, Keller U, Müller B: In vitro and in vivo calcitonin I gene expression in parenchymal cells: a novel product of human adipose tissue. Endocrinology 2003, 144:5578-5584 
55. Lucas R, Verin AD, Black SM, Catravas JD: Regulators of endothelial and epithelial barrier integrity and function in acute lung injury. Biochem Pharmacol 2009, 77:1763-1772

56. Summers C, Rankin SM, Condliffe AM, Singh N, Peters AM, Chilvers ER: Neutrophil kinetics in health and disease. Trends Immunol 2010, 31:318-324

57. Meduri GU, Kohler G, Headley S, Tolley E, Stentz F, Postlethwaite AI: Inflammatory cytokines in the BAL of patients with ARDS: persistent elevation over time predicts poor outcome. Chest 1995, 108:1303-1314

58. Natanson C, Hoffman WD, Suffredini AF, Eichacker PQ, Danner RL: Selected treatment strategies for septic shock based on proposed mechanisms of pathogenesis. Ann Intern Med 1994, 120:771-783

59. Standiford TJ, Strieter RM, Lukacs NW, Kunkel SL: Neutralization of IL-10 increases lethality in endotoxemia: cooperative effects of macrophage inflammatory protein-2 and tumor necrosis factor. $\mathrm{J}$ Immunol 1995, 155:2222-2229

60. Lang R, Patel D, Morris JJ, Rutschman RL, Murray PJ: Shaping gene expression in activated and resting primary macrophages by IL-10. J Immunol 2002, 169:2253-2263

61. Lentsch AB, Shanley TP, Sarma V, Ward PA: In vivo suppression of $\mathrm{NF}-\kappa \mathrm{B}$ and preservation of $\mathrm{I} \kappa \mathrm{B} \alpha$ by interleukin-10 and interleukin-13. J Clin Invest 1997, 100:2443-2448

62. Van der Poll T, Marchant A, Buurman WA, Berman L, Keogh CV, Lazarus DD, Nguyen L, Goldman M, Moldawer LL, Lowry SF:
Endogenous IL-10 protects mice from death during septic peritonitis. J Immunol 1995, 155:5397-5401

63. Kono H, Fujii H, Tsuchiya M, Hirai Y, Ishii K, Hosomura N, Tanaka N: Inhibition of the Kupffer cell and neutralization of IL-10 increase the expression of chemokines in the lung in a rat peritonitis model. J Surg Res 2008, 150:169-182

64. Walley KR, Lukacs NW, Standiford TJ, Strieter RM, Kunkel SL: Elevated levels of macrophage inflammatory protein 2 in severe murine peritonitis increase neutrophil recruitment and mortality. Infect Immun 1997, 65:3847-3851

65. Schmal H, Shanley TP, Jones ML, Friedl HP, Ward PA: Role for macrophage inflammatory protein-2 in lipopolysaccharide-induced lung injury in rats. J Immunol 1996, 156:1963-1972

66. Schall TJ, Bacon K, Toy KJ, Goeddel DV: Selective attraction of monocytes and T-lymphocytes of the memory phenotype by cytokine RANTES. Nature 1990, 47:669-671

67. Monneret G, Arpin M, Venet F, Maghni K, Debard AL, Pachot A, Lepape A, Bienvenu J: Calcitonin gene related peptide and N-procalcitonin modulate CD11b upregulation in lipopolysaccharide activated monocytes and neutrophils. Intensive Care Med 2003, 29: 923-928

68. Ghosh S, Hayden MS: New regulators of NF-kappaB in inflammation. Nat Rev Immunol 2008, 8:837-848

69. Fan J, Ye RD, Malik AB: Transcriptional mechanisms of acute lung injury. Am J Physiol Lung Cell Mol Physiol 2001, 281:L1037-L1050 